\title{
A ADAPTAÇÃO DE PRÁTICAS DE ORALIDADE EM LÍNGUA INGLESA COMO L2 DE MODO PRESENCIAL PARA REMOTO
}

\author{
Claudia Marchese Winfield ${ }^{{ }^{*}}$ \\ Ana Flávia Will ${ }^{* *}$ \\ ${ }^{1}$ Universidade Tecnológica Federal do Paraná, Pato Branco, PR, Brasil
}

\begin{abstract}
Resumo
O presente artigo aborda a adaptação ao modo remoto do projeto presencial intitulado Movie Talks, desenvolvido em 2018 como projeto de extensão da UTFPR - Pato Branco. O objetivo deste estudo é relatar as mudanças que se fizeram necessárias quando da reestruturação do projeto para a versão remota, buscando tornar o projeto online acessível, contextualizado e significativo para os participantes, por meio de diferentes recursos digitais para a realização de atividades voltadas para a oralidade e escrita autônomas e significativas. $\mathrm{O}$ artigo está pautado na pesquisa bibliográfica, majoritariamente nos estudos de Brown (2000), Chartrand (2012), Woo et al. (2007) e outros, a partir dos princípios de automaticidade, aprendizagem significativa, motivação intrínseca e investimento estratégico na utilização de recursos tecnológicos no ensino de línguas no modo remoto emergencial.

Palavras-chave: Ensino remoto emergencial; recursos digitais; princípios cognitivos
\end{abstract}

\section{THE ADAPTATION OF SPEAKING PRACTICES IN ENGLISH AS AN L2 FROM IN-PERSON TO REMOTE MODE}

\begin{abstract}
This article discusses the adaptation to remote mode of an in-person project entitled Movie Talks that was developed in 2018 as an extension project at UTFPR - Pato Branco. The aim of this study is to report the changes that have become necessary when restructuring the project for the remote version, in order to make the online project accessible, contextualized and meaningful for the participants, through an array of digital resources to carry out activities aimed at autonomous and
\end{abstract}

\footnotetext{
* Professora adjunta na Universidade Tecnológica Federal do Paraná e doutora em Estudos da Linguagem. Seu interesse acadêmico está voltado para o ensino-aprendizagem de língua inglesa, bem como os aspectos cognitivos da leitura em língua inglesa e a interação destes com os processos cognitivos da escrita em língua inglesa e tradução. E-mail: claudiam@utfpr.edu.br. Orcid: https://orcid.org/0000-0002-3215-2506.

** Bacharel em Direito e atualmente Mestranda do Programa de Pós-Graduação em Letras da Universidade Tecnológica Federal do Paraná. Suas pesquisas acadêmicas abrangem o ensino-aprendizagem de línguas e estudos da tradução. E-mail: anawill@alunos.utfpr.edu.br. Orcid: https://orcid.org/0000-0001-6319-2159.
} 
meaningful oral and written comprehension and production. This article is based on bibliographic research, mainly on the studies of Brown (2000), Chartrand (2012), Woo et al. (2007) and others, based on the principles of automaticity, meaningful learning, intrinsic motivation and strategic investment using technological resources for language teaching in the emergency remote mode.

Keywords: Emergency distance learning; digital resources; cognitive principles 


\section{Introdução}

No presente artigo, apresenta-se a adaptação de um projeto de extensão presencial voltado para o desenvolvimento da oralidade em língua inglesa para o modo remoto, em virtude da pandemia do coronavírus, a qual se iniciou no Brasil em 2020. O projeto intitulado Movie Talks (WINFIELD, 2018) é um projeto de extensão da Universidade Tecnológica Federal do Paraná, campus Pato Branco, que ofereceu encontros periódicos para prática de conversação em inglês a partir da exibição de curtas-metragens. O objetivo do projeto foi o desenvolvimento da fluência oral em língua inglesa a partir de práticas contextualizadas com o intuito de envolver os participantes em uso significativo da língua inglesa (BROWN, 2000; CHARTRAND, 2012; LONG; DOUGHTY, 2009; SKEHAN, 1998; WOO et al., 2007). Originalmente, ainda no formato presencial, o projeto desenvolveu suas atividades em parceria com a Secretaria de Cultura de Pato Branco, na Biblioteca Municipal Professora Helena Braun, em sessões mensais aos sábados pela manhã entre outubro de 2018 e dezembro de 2019.

Com a suspensão de atividades presenciais devido à pandemia do coronavírus, decidiu-se oferecer sessões online síncronas via Google Meet, que integra o pacote G suite oferecido pela UTFPR (2020). Entretanto, a transição de atividades interacionais de modo presencial para modo remoto é recente. Supõese que não seja suficiente apenas passar os encontros presenciais para encontros online utilizando o recurso digital de videoconferência: faz-se necessária a adaptação de práticas e recursos digitais. O presente artigo relata tais adaptações com a finalidade de tornar o projeto em modo remoto acessível, contextualizado e significativo para seus participantes.

Considerando a transição das atividades presenciais para o modo remoto, é importante destacar que autores oriundos das áreas de ensino superior e psicólogos apontam para os percalços do ensino remoto emergencial. Entre os principais desafios, está a adaptação dos estudantes ao ensino remoto, os quais muitas vezes não apresentam níveis suficientes em habilidades acadêmicas como leitura e escrita, comprometendo a autonomia necessária para gerenciar o seu processo de aprendizagem em modo remoto. Outro desafio identificado é a falta de habilidade de utilização de recursos digitais por parte de professores e estudantes, pois ambos podem ter pouco contato com certas mídias mais recentes (GUSSO et al., 2020).

Tendo em mente as particularidades mencionadas, a adaptação do projeto de extensão relatada neste artigo não se limita ao oferecimento de práticas por meio de plataformas digitais para possibilitar o encontro em modo remoto, mas sim uma reformulação das atividades do projeto envolvendo momentos síncronos e assíncronos. As atividades síncronas são descritas neste trabalho por meio de uma amostra do planejamento das práticas orais organizadas para o trabalho com o gênero curta-metragem, enquanto as atividades assíncronas são exemplificadas por meio de uma proposta de criação de podcast. Para criação de um podcast, serão necessárias a leitura e escrita complementares às práticas de oralidade realizadas sincronicamente, oferecendo assim, a oportunidade de melhoria nas habilidades de leitura e escrita em 
língua inglesa dos participantes do projeto. Também se possibilita a familiarização dos participantes com recursos digitais como o Google Meet, Google Forms, infográficos, blogs e podcasts no projeto oferecido em modo remoto.

Para o processo de adaptação do projeto, primeiramente, alterou-se o seu nome para Movie Talks Online (WINFIELD, 2021) e foi realizada a reelaboração das atividades do projeto conforme mencionado anteriormente, bem como uma nova seleção de materiais fílmicos. As atividades serão coordenadas pela professora orientadora do projeto e estudantes voluntários e acontecerão de junho a julho de 2021, seguindo o cronograma e descrição dispostos no Apêndice A.

Em relação à seleção dos materiais utilizados no projeto (WINFIELD, 2021), foram utilizados materiais autênticos levando-se em consideração questões de direito autoral e direitos conexos. Buscaram-se curta-metragens oriundos de três fontes que disponibilizam materiais passíveis de compartilhamento. Uma das fontes é o site Creative Commons, uma organização não governamental sem fins lucrativos dedicada à padronização de reprodução, compartilhamento, edição, adaptação e utilização de trabalhos criativos equilibrando o direito autoral e os direitos conexos (CREATIVE COMMONS, 2021). O site possui um repositório de imagens, áudios e vídeos dentre os quais foram selecionados três filmes em curta-metragem para o projeto supracitado.

A segunda fonte é proveniente de um programa intitulado Pandemic Film Challenge oferecido pelo departamento de Língua Inglesa, do Dietrich College of Humanities and Social Sciences, na Carnegie Mellon University (CARNEGIE MELLON UNIVERSITY, 2020). O programa intenciona proporcionar interação entre a comunidade acadêmica por meio de curtas criados por seus alunos voltados para o tema da pandemia. Além do tema, o desafio proposto pelo professor Jeff Hinkelman previa que os curtas deveriam ter duração máxima de cinco minutos. Sendo assim, os alunos criaram curtas de vários gêneros incluindo documentários, comédias, animações, narrativas, entre outros. Dois desses trabalhos foram selecionados para o Movie Talks online.

A terceira fonte é a editora independente Film English que possui um vasto acervo online de curta-metragens utilizados como materiais pedagógicos, incluindo planos de aula e guias para espectador, entre outros. Os materiais são comercializados pela editora para uso pedagógico (DONAGHY, 2021) e, para o propósito deste projeto de extensão, a coordenadora adquiriu dois materiais. São eles os planos de aula intitulados "A Thousand Words" e "Umbrella", que incluem o acesso aos respectivos curtas-metragens. A adaptação das práticas e recursos utilizados no projeto Movie Talks Online são discutidos a seguir.

\section{Movie Talks online - Em busca de Práticas Contextualizadas e Significativas para Desenvolvimento da Fluência Verbal em Língua Inglesa em Modo Remoto}

O principal objetivo do projeto é o desenvolvimento da fluência verbal em língua inglesa por meio de práticas contextualizadas e significativas, pois 
esta é uma das principais características da habilidade de fala. No que tange ao desenvolvimento da língua inglesa como língua estrangeira (LE), segunda língua (L2), língua adicional (LA) ou língua franca (LF), pode-se definir a fluência verbal como "a habilidade do falante falar sem esforço aparente com poucas pausas ou hesitações na língua-alvo e com precisão suficiente para ser entendido pelo interlocutorl" (RYCZEK, 2013, p. 32, tradução livre), considerando que pausas ou hesitações excessivas tendem a comprometer a interação entre falantes (DE JONG; PERFETTI, 2011; RYCZEK, 2013; SEGALOWITZ, 2016; SEGALOWITZ; FRENCH; GUAY, 2017). Para o propósito deste trabalho, adota-se o L2 como um termo "guarda-chuva" para língua estrangeira, segunda língua, língua adicional ou língua franca, pois o presente projeto foi desenhado de modo a adaptar-se para participantes com experiência da língua inglesa como LE, L2, LA ou LF, visto que a fluência e expressão oral são possíveis para todas essas experiências. Além do mais, o projeto não propõe um modelo ideal de falante a ser almejado pelos participantes, muito pelo contrário, pretende possibilitar formas de expressão a todos, valorizando suas diferenças e vivências individuais.

Sendo assim, quatro princípios cognitivos norteiam a proposta: automaticidade como condição necessária para fluência, aprendizagem significativa, motivação intrínseca e investimento estratégico. As atividades do projeto pretendem criar oportunidades de prática oral para os participantes que levem ao desenvolvimento de fluência verbal, considerando o consenso de estudos na área de ensino-aprendizagem em relação à importância de práticas contextualizadas e significativas para a melhor retenção e à fluência no desenvolvimento da L2 (BROWN, 2000). Ademais, as práticas contextualizadas e significativas reforçam a autoconfiança e a predisposição para o engajamento nas atividades que envolvem a expressão oral (WOO et al., 2007).

No que tange à automaticidade, destaca-se a importância da exposição dos falantes de L2 ao input, pois, por meio da exposição, possibilita-se a aprendizagem implícita, que ocorre sem atenção explícita do falante da L2 para a forma da língua-alvo. As pesquisas mostram que a aprendizagem implícita pode ocorrer quando as práticas de linguagem são contextualizadas e focam-se no uso e sentido, em vez dos aspectos formais da linguagem. Para tal, sugeremse uso de materiais, e se, possível, situações autênticas. Ademais, Brown (2000) afirma que o desenvolvimento da L2 requer o seu controle e processamento automático, por isso, a atenção demasiada às formas linguísticas tende a dificultar a automatização da linguagem. O projeto Movie Talks Online (WINFIELD, 2021) oferece a oportunidade de desenvolvimento da linguagem por meio de input autêntico, que é explorado de modo contextualizado, com ênfase na construção de sentido a partir do input, ou seja, os curtas-metragens.

Em relação à aprendizagem significativa, esta é caracterizada pela subordinação de informação nova a estruturas existentes nos sistemas de memória dos aprendizes, gerando conexões associativas que resultam em mais forte retenção de informações. Portanto, informações contextualizadas e relacionadas ao conhecimento prévio dos aprendizes conduzem a melhor retenção de 
informações ou linguagens novas. Fortemente recomendado para propostas de experiências significativas de uso, aprendizagem ou desenvolvimento de uma L2 é a utilização de materiais autênticos. De fato, a importância do uso de contextos e materiais autênticos tem sido defendida por muitos autores da área há algum tempo (AEBERSOLD; FIELD, 1997; BROWN, 2000; LEFFA, 2008; TOMLINSON, 2016; TOMITCH, 2009, entre muitos outros) e intensificou-se nas proposições de recursos digitais para o desenvolvimento de L2 (CHARTRAND, 2012; LEFFA, 2017; LOSADA; INSUASTI; JAIME, 2017; TUMOLO, 2014; WOO et al., 2007 entre muitos outros). $\mathrm{O}$ uso de contextos e materiais autênticos aproxima a linguagem à realidade do aprendiz da L2, possibilitando a conexão entre seu conhecimento prévio e os conteúdos temáticos e linguísticos a serem abordados em uma experiência de desenvolvimento de L2.

Ademais, a aprendizagem significativa envolve o princípio da motivação, em especial a motivação intrínseca, sugerido por Brown (2000) a partir da teoria de autodeterminação de Deci e Ryan (1985). Em relação à motivação, por uma perspectiva behaviorista, esta pode ser definida como o comportamento humano motivado por um objetivo externo como uma gratificação, por exemplo, e o esforço empregado para a sua realização. Por outro lado, sob o ponto de vista cognitivo, a motivação envolve outros fatores, internos ao indivíduo, como a satisfação em aprender ou realizar algo, ou contextuais também, por exemplo, a necessidade de aprender uma língua estrangeira para obter uma promoção no emprego. Para as situações de desenvolvimento da L2, a saber: a motivação intrínseca merece atenção, pois está bastante associada com aprendizagem. Autores como Dõrnyei (2001), Dõrnyei e Ushioda (2011) e Ehrman e Dõrnyei (1998) também têm investigado o construto, desenvolvido teorias e estabelecido distinções entre os tipos de motivação.

Para o presente artigo, apresentam-se dois tipos de motivação, a motivação extrínseca e a intrínseca. Como o termo indica, a motivação extrínseca é oriunda de fatores externos ao aprendiz, como as notas e as gratificações resultantes da aprendizagem. No caso do desenvolvimento da L2, a motivação extrínseca pode estar ligada à obtenção de boas notas no contexto escolar, por exemplo, ou a processos de seleção da vida acadêmica como aqueles presentes em programas de mestrado ou doutorado, ou até mesmo recompensas na vida profissional do indivíduo. Por outro lado, a motivação intrínseca refere-se a fatores internos. No caso do desenvolvimento da L2, a motivação intrínseca expressa-se na satisfação, na experiência da aprendizagem ou desenvolvimento da L2 em si, satisfação essa que não depende de gratificações externas. Estudos sobre a aprendizagem de L2 indicam que a motivação intrínseca tem maior correlação com a aprendizagem, porém a motivação geral do aprendiz parece envolver uma combinação entre fatores extrínsecos e intrínsecos.

Por fim, o princípio do investimento estratégico proposto por Brown (2000) é provocado pela mudança de paradigma da aprendizagem centrada no professor, para aprendizagem centrada no aprendiz. Dessa forma, o investimento estratégico caracteriza-se pela necessidade de envolvimento do aprendiz em seu 
próprio desenvolvimento linguístico, dedicando seu tempo, esforço, atenção e estratégias individuais para desenvolver a sua L2. No que tange às estratégias individuais, o autor destaca a necessidade de promoção de atividades variadas para que diferenças individuais de estilo de aprendizagem sejam compreendidas. O projeto Movie Talks Online (WINFIELD, 2021) contempla esse princípio, pois oferece aos participantes atividades síncronas e assíncronas variadas, explorando a oralidade, bem como a leitura e a escrita. Também se oferecem gêneros diversificados como os curtas-metragens, como infográficos, podcasts ou blogs nas atividades assíncronas previstas no projeto.

De modo geral, as atividades previstas no projeto preveem variedade de temas e estratégias para a abordagem do gênero curta-metragem para a aprendizagem da língua inglesa com o intuito de promover a retenção dos conteúdos trabalhados, assim como adequar esta experiência a diferentes estilos de aprendizagem que os participantes possam apresentar (BROWN, 2000). O projeto volta-se para aprendizagem significativa uma vez que se encontra pautado na abordagem de um gênero bastante utilizado na contemporaneidade e trata de temas relevantes para a época. Outrossim, o projeto oferece oportunidade de reflexão individual e conjunta acerca das obras e temas explorados no projeto, pretendendo, dessa forma, criar oportunidade de autoexpressão e gerar motivação por parte dos participantes.

\section{Amostra do Planejamento das Práticas com Gênero Curta- Metragem - Atividades Síncronas}

Nesta seção apresenta-se uma amostra do planejamento para as práticas linguísticas, comunicativas e discursivas com um dos curtas-metragens selecionados para o projeto, o curta Umbrella (UMBRELLA, 2020). A obra é uma produção brasileira independente produzida pelo estúdio Stratostorm e qualificada para o Oscar de 2021. Baseado em fatos reais, Umbrella conta a história de um menino, Joseph, que é fascinado por um guarda-chuva amarelo. Um dia o menino conhece uma garota que tem um guarda-chuva amarelo e a narrativa desenvolve-se a partir desse encontro.

Quadro 1: Planejamento para práticas de oralidade a partir do curta-metragem Umbrella

\begin{tabular}{|l|l|}
\hline Título da sessão & Umbrella, a Brazilian animation by Hilario and Pece (UMBRELLA, 2020) \\
\hline Duração da sessão & 90 minutos \\
\hline Público-alvo & $\begin{array}{l}\text { Adultos e jovens adultos participantes do projeto Movie Talks Online, com } \\
\text { níveis heterogêneos de proficiência em língua inglesa. }\end{array}$ \\
\hline Temática da sessão & Empatia, abandono, infância. \\
\hline Objetivos da sessão & $\begin{array}{l}\text { Expandir o léxico e o tema relacionado à infância como atividade prévia ao } \\
\text { filme } \\
\text { Assistir ao curta Umbrella; } \\
\text { Predizer o desenvolvimento do enredo do filme; } \\
\text { Relembrar as principais ações do enredo do filme; } \\
\\
\text { Discutir os temas de empatia, abandono e infância; } \\
\text { Desenvolver escrita colaborativa. }\end{array}$ \\
\hline
\end{tabular}




\begin{tabular}{|l|l|}
\hline Sequência de atividades da sessão & $\begin{array}{l}\text { Atividade propostas prévias ao filme: ativação do conhecimento prévio dos } \\
\text { participantes sobre infância e brinquedos para a narrativa a ser exibida, } \\
\text { seguida de atividade de predição (Apêndice B). } \\
\text { Atividades propostas durante o filme: assistir ao curta em partes para } \\
\text { predição dos eventos da narrativa e relembrar as principais ações do enredo } \\
\text { do filme (Apêndice C). } \\
\text { Atividades propostas após o filme: discussão das temáticas envolvidas no } \\
\text { curta-metragem e escrita colaborativa sobre as impressões geradas sobre o } \\
\text { filme e a discussão (Apêndice D). }\end{array}$ \\
\hline Recursos necessários & $\begin{array}{l}\text { Acesso a celular, notebook, Iphone, tablet ou computador de mesa; conexão } \\
\text { de internet; acesso ao Google Meet, Google Forms e Google Drive. }\end{array}$ \\
\hline & \\
\hline
\end{tabular}

Fonte: As autoras.

O planejamento das atividades elencadas no Quadro 1 leva em consideração os princípios da automaticidade, aprendizagem significativa, motivação intrínseca e investimento estratégico previamente mencionados. Além do mais, a proposta privilegia a fluência e a expressão de ideias. $\mathrm{Na}$ amostra de planejamento de para práticas de oralidade a partir de curta-metragem, apresentamos o plano para o filme Umbrella de Hilário e Pece (UMBRELLA, 2020), com o propósito de evidenciar a inclusão dos princípios cognitivos supracitados nas práticas oferecidas.

Baseando-se no uso significativo da língua (BROWN, 2000; CHARTRAND, 2012; LONG; DOUGHTY, 2009; SKEHAN, 1998; WOO et al., 2007), que por sua vez, requer a contextualização do material a ser trabalhado, inicialmente, propõese uma atividade de prévia à exibição do filme (Apêndice B). Conforme é possível notar no Quadro 1, a etapa envolve a ativação do conhecimento prévio dos participantes sobre a infância e brinquedos por meio da formação de uma nuvem de palavras utilizando o recurso menti.com, evocando o vocabulário relacionado a brinquedos. Ao evocar o vocabulário, os participantes ativam e expandem seu repertório lexical e começam a criar uma ideia sobre o tema do curta-metragem. Posteriormente, a mediadora da sessão faz uma pergunta "Why might a young boy want an umbrella more than any toy?" (DONAGHY, 2020, p.3) com o intuito de levar os participantes à predição acerca da narrativa. A pergunta é de relação causal, por isso, acredita-se que esta motive os participantes a criarem hipóteses e desperte a sua curiosidade. Portanto, as atividades prévias ao filme apresentam o potencial de promover o princípio da motivação intrínseca (BROWN, 2000; DÕRNYEI, 2001; DÕRNYEI; USHIODA, 2011; EHRMAN; DÕRNYEI, 1998).

Subsequentemente, estãoplanejadasatividadesrealizadasconcomitantemente à exibição do filme (Apêndice C). Nessa etapa, a mediadora deverá exibir a primeira parte do curta. A seguir, ela irá propor as perguntas abaixo:

1. What colour is the scarf the boy is wearing?

2. What colour are the boy's eyes?

3. What does the boy draw on the window?

4. How does the boy feel? 
5. What colour are the girl's eyes?

6. How does the girl feel?

7. How does the boy react when he sees the yellow umbrella?

8 . What do the mother and daughter bring to the home for children?

(DONAGHY, 2020, p. 5)

Durante a interação dos participantes, deve-se manter o foco na construção de sentido e na fluência, sem se ater a questões formais da língua inglesa. Essa atividade engloba os princípios da aprendizagem significativa, pois se trata de prática contextualizada, a partir de material autêntico que prevê a interação entre os alunos. Esse será um processo de construção gradual da narrativa. Além disso, duas perguntas criadas pelas autoras deste artigo são adicionadas e propostas após a exibição da segunda parte do filme, são elas:

9. Why did the boy (Joseph) take the yellow umbrella? 10. Where did he hide it?

As perguntas propostas são de diferentes níveis de complexidade, de modo a dar oportunidade a participantes com diferentes níveis de proficiência no idioma, diferentes estilos de aprendizagem, já que algumas perguntas são voltadas para informações visuais (perguntas $1,2,3,5,8$ ) e outras são de ordem mais alta, requerem o estabelecimento de causa e efeito e inferências sobre o estado emocional dos personagens (perguntas 4, 6, 7, 9, 10). Portanto, devido à sua variedade, o conjunto de perguntas propostas possibilita o investimento estratégico dos participantes (BROWN, 2000), estando também, intimamente ligado à motivação intrínseca (BROWN, 2000; DÕRNYEI, 2001; DÕRNYEI; USHIODA, 2011; EHRMAN; DÕRNYEI, 1998).

Após essa etapa, o filme é exibido até o seu final e propõe-se uma atividade de ordenação das partes do filme (Apêndice C). São listadas frases que descrevem os eventos fora da ordem correta. Para ordenar os eventos, os participantes precisarão lembrar da sequência da narrativa. Além de lembrar dos eventos, os participantes deverão se engajar na leitura das frases, mais uma vez, construindo verbalmente a narrativa do curta-metragem. A reconstrução da narrativa prevista em todas as atividades propostas durante o filme constitui um exemplo de aprendizagem significativa que pode beneficiar a automaticidade (BROWN, 2000), pois conforme previamente discutido, práticas de linguagem contextualizadas e voltadas para construção de sentido possibilitam a aprendizagem implícita a partir de input significativo.

Por fim, será desenvolvida uma discussão das temáticas do filme, ou seja, infância, abandono, empatia, além de prática de escrita colaborativa como atividades propostas após o filme (Apêndice D). O propósito da discussão é permitir a expressão de ideias, assim como incentivar o pensamento crítico acerca das questões relacionadas ao curta-metragem. Complementando a discussão, será proposta a escrita colaborativa como produção final da sessão. O gênero textual sugerido é uma sinopse sobre o filme, dadas a característica e finalidade 
do gênero, ou seja, para transmitir concisamente as informações básicas da obra, pressupõe-se o processo de lembrança (recall) da narrativa. Sendo assim, é possível supor que a atividade facilite a automaticidade e constitua uma atividade significativa.

De acordo com o exposto, considera-se que as atividades síncronas contemplem os princípios cognitivos de acordo com Brown (2000), além de atenderem às necessidades apontadas por Gusso et al. (2020) para a adaptação de experiências de aprendizagem presenciais para modo remoto emergencial, pois houve uma reestruturação das práticas propostas. $\mathrm{O}$ projeto anterior, o Movie Talks presencial (WINFIELD, 2018), era predominantemente voltado para conversação a partir de um input, usando o gênero curta-metragem. Alternativamente, o Movie Talks Online (WINFIELD, 2021) prevê práticas com/ em habilidades acadêmicas como leitura e escrita, intencionadas à autonomia dos estudantes para aprendizagem em modo remoto emergencial conforme alertado pelos autores.

\section{O Uso de Recursos Digitais para Integração de Oralidade, Leitura e Escrita - Atividades Assíncronas}

Ainda pautada nas necessidades destacadas por Gusso et al. (2020), as atividades assíncronas têm por finalidade fortalecer as práticas de leitura e escrita em L2, assim como propiciar o contato com mídias mais recentes seguindo a premissa do uso de materiais autênticos para promoção de aprendizagem significativa. De fato, em ambientes de aprendizagem virtual, a possibilidade de promoção de diferentes atividades também traz a viabilidade do ensino construtivista através de atividades autênticas. Com a utilização de uma variedade de recursos multimidiáticos e uma gama de informações disponíveis online, é possível criar tarefas em diferentes formatos, utilizando desde textos até vídeos que contribuem também para a motivação do aluno (WOO et al., 2007).

De modo semelhante, Chartrand (2012) sugere a utilização de materiais autênticos criados pelos próprios alunos, como o podcast, como maneira de motivá-los à utilização da língua em uma perspectiva de aprendizado construtivista, com produção significativa e contextualizada. Essa possibilidade advém da internet enquanto meio e recurso para a criação autêntica de materiais que, neste projeto, podem ser utilizados de maneira complementar às atividades síncronas, em especial no contexto de interação assíncrona em que o aluno desenvolve suas atividades de maneira independente. Assim, o aluno interage de maneira significativa na aquisição e motivação para o aprendizado da L2.

\section{Uso de Podcasts para Incremento de Práticas Voltadas para a Oralidade - Atividades Assíncronas}

Para as atividades assíncronas do projeto Movie Talks Online (WINFIELD, 2021), constam uma série de recursos e atividades que podem ser desenvolvidas 
e adaptadas, de acordo com a necessidade, evolução e nível de proficiência na língua inglesa dos participantes. Para fins didáticos, neste artigo escolheu-se abordar com maior aprofundamento o gênero podcast, que será utilizado em atividade assíncrona do projeto.

O gênero podcast é descentralizado e democrático em relação às grandes mídias, pois não há exigências particulares quanto aos seus produtores (MEDEIROS, 2005). Está presente nas práticas sociais em ambientes virtuais cotidianas e oferece possibilidade de utilização como instrumento de ensino de língua inglesa para o desenvolvimento da oralidade de forma que o participante assuma uma posição de agência, por meio da qual assume autonomia para, de certa forma, conduzir seu próprio aprendizado. Deixa-se o papel de mero consumidor da mídia para assumir a posição de designer, criador, produtor (ROHLING, 2021).

Ademais, nos contextos de ensino-aprendizagem em ambientes controlados e de menor exposição, a participação em processos de criação de podcasts permite que os participantes desenvolvam sua expressividade em língua inglesa com maior segurança (GAROFALO, 2019). Considerando as vantagens supracitadas, partir de diferentes propostas e metodologias relativas ao design de podcasts (ROHLING, 2021; GAROFALO, 2019; SARAIVA et al., 2018), sugere-se um roteiro em quatro etapas para a criação do podcast no âmbito das atividades assíncronas do projeto em questão, conforme disposto no Quadro 2:

Quadro 2: Roteiro para criação do podcast

\section{Roteiro para a criação de podcast}

\section{Etapa 1: O Planejamento}

Inicialmente, deve-se escolher cuidadosamente a temática a ser elaborada no podcast. Realizar pesquisas aprofundadas e organizar os pontos sobre o assunto a serem abordados é o primeiro passo, seguido da identificação de palavras-chave acerca da temática que poderão ser revisitadas no decorrer do podcast e da escolha de abordagem, que influenciará inclusive na linguagem a ser utilizada. $\mathrm{O}$ formato a ser apresentado também é relevante, pois uma estrutura de narrativa ou semelhante a um noticiário será consideravelmente diferente de entrevistas, por exemplo. Caso se opte por um formato de entrevista, é necessário escolher quem será convidado para participar, considerando a possível contribuição para o assunto. Nesse momento também se deve considerar quem será o público ouvinte, se haverá a possibilidade de interação posterior à divulgação e qual é a motivação que levou à produção desse podcast (créditos acadêmicos, atividade assíncrona em projeto de extensão, interesse em mídias comunicativas, etc.).

\section{Etapa 2: O Roteiro}

Após a organização do podcast, será necessário escrever o roteiro a ser apresentado. O roteiro deve utilizar linguagem condizente com o contexto, o gênero e os objetivos da abordagem. $O$ roteiro deve ser escrito em inglês e os participantes poderão estruturar os textos de acordo com a necessidade para o formato do podcast pelo qual optaram na etapa anterior. Após a escrita, deve-se revisar o texto, corrigir eventuais desvios. É relevante atentar-se à especificidade do texto, que será posteriormente reproduzido de maneira oral e, portanto, seria adequado utilizar palavras de pronúncia mais fácil, quando possível, e organizar as frases de forma que seja prático para ler. Por fim, o participante deverá ensaiar a leitura do texto, marcando as pausas da fala onde necessário, adequando a velocidade e ritmo da fala e trocando palavras caso haja necessidade para facilitar a pronúncia e a compreensão pelo ouvinte. 


\section{Etapa 3: As Gravações}

Com o roteiro já pronto, o participante inicia a gravação. É importante escolher um local de gravação adequado, para que não haja interferência de ruídos externos. Para esse processo, é possível utilizar recursos de gravação em diferentes dispositivos eletrônicos, como computadores de mesa com microfone externo, notebooks ou até mesmo celulares. Essa gravação pode ser refeita, caso seja necessário, quantas vezes seja preciso. Com o áudio já elaborado, o participante irá realizar a edição do podcast, inserindo efeitos sonoros e trilhas sonoras que se encaixem com a proposta, ou cortando trechos em que as marcas da oralidade (como pausas, hesitações e repetições) possam afetar a compreensão do ouvinte. Para isso, caso o participante deseje, é possível utilizar uma variedade de aplicativos ou websites que disponibilizam a função de edição de áudio gratuitamente online. Entretanto, reitera-se que o participante pode optar por gravar seu podcast no dispositivo que preferir e/ou tiver acesso, ou mesmo não realizar a edição de seu podcast.

\section{Etapa 4: O Resultado Final}

Após a conclusão das três etapas anteriores, o participante terá em mãos o resultado final: um podcast autoral, elaborado através de pesquisa e muita prática no uso de diferentes habilidades na língua inglesa. Considerando as peculiaridades e objetivos da produção do gênero, o podcast precisa ser compartilhado. Esse compartilhamento ocorrerá inicialmente através da entrega da atividade, via Google Classroom ou outra plataforma, à coordenação do projeto dentro do qual este foi desenvolvido ou, em se tratando de produção independente, da publicação para acesso pelo público. É possível, após a avaliação interna das produções, que essas sejam compartilhadas em redes sociais, canais institucionais, outras mídias ou plataformas específicas de podcasts, para a divulgação do conhecimento e das produções autorais. Embora não seja um gênero que requer ou mesmo que possibilite uma frequente interação do público com os podcasters, essa ainda é uma possibilidade e, dependendo do objetivo e forma de publicação, pode ser interessante abrir espaço para a interação direta com os interlocutores.

Fonte: As autoras.

Conforme o modelo proposto para o desenvolvimento do podcast, identificase que: a Etapa 1 (O Planejamento) aborda a habilidade de leitura em L2 para a coleta de dados; a Etapa 2 (O Roteiro) está relacionada à habilidade de produção escrita e uso da língua em L2 para a criação do texto a ser gravado; a Etapa 3 (As Gravações) está conectada à habilidade de produção oral em L2 e, no caso dos futuros interlocutores do podcast, também se interrelacionam com a interpretação oral em L2; a Etapa 4 (O Resultado Final) é o momento em que todas as habilidades anteriores convergem para um ponto em que as habilidades sejam integradas e gerem o resultado esperado. Conforme exposto por Tumolo (2014), a integração de leitura, escrita e oralidade possibilita o uso do input autêntico em situação real de interação, na mesma linha em que Brown (2000), Tomlinson (2016) sugerem a relação entre o uso de material autêntico e a aprendizagem significativa. Vale lembrar que, em situação real, não se fragmenta o uso da língua em habilidades de fala, compreensão oral, escrita e leitura.

Enquanto atividade do projeto, a proposta é que o podcast utilize como base o curta Umbrella (UMBRELLA, 2020), anteriormente descrito neste artigo, que aborda questões da infância, memórias, empatia e abandono. Os participantes do projeto deverão produzir seu próprio podcast desenvolvido em um formato de episódio único. Como a elaboração de um podcast necessita de letramento específico, será incluído no projeto, uma sessão de familiarização com a elaboração e produção de podcast como recurso educacional aberto pelas autoras do presente artigo. 
Após o momento de estímulo da leitura em língua inglesa, em que os participantes deverão acessar o website produzido especialmente para a divulgação de informações sobre o curta (UMBRELLA MOVIE, 2021) e realizar pesquisas acerca do tema escolhido para a produção, deverão então escrever um roteiro original em inglês, a respeito de temática relacionada. $\mathrm{O}$ roteiro escrito, além de promover a prática da habilidade de escrita na língua, também servirá como guia para o posterior desenvolvimento do podcast, que deverá ser então gravado (etapa de desenvolvimento da habilidade de oralidade), editado e entregue à organização do projeto, possivelmente via Moodle ou outra plataforma disponibilizada pela universidade para uso em atividades educacionais online. Os podcasts serão recebidos, avaliados e então far-se-á momento de devolutiva, incluindo-se sugestões e eventuais correções que se mostrem necessárias. Por ora, a perspectiva de divulgação das produções dos participantes ainda está sob análise. É possível adaptar ao contexto, considerando as opções disponíveis no local de desenvolvimento do projeto, para divulgar as produções em redes sociais, blogs, entre outros.

Portanto, a proposta de elaboração de podcasts contempla os princípios cognitivos de automaticidade, tendo em vista o seu processo de elaboração que integra as habilidades comunicativas na produção de um recurso abordando a temática escolhida, assim como o princípio da aprendizagem significativa, pois a criação de podcast consiste na elaboração de material a ser utilizado de forma contextualizada. Considerando o engajamento necessário para a elaboração do podcast, pode-se supor que tal prática envolve o princípio do investimento estratégico, assim como a motivação intrínseca, previamente discutidos neste artigo.

\section{Considerações Finais}

Neste trabalho, foi detalhado o processo de adaptação de um projeto presencial voltado para o desenvolvimento da oralidade em língua inglesa com foco na fluência para o modo remoto emergencial de modo a oferecer práticas contextualizadas e significativas para seus participantes. Devido ao caráter emergencial da transição, foram consideradas algumas particularidades e necessidades, tais quais necessidade de adaptação, que não se limitam somente à transferência de encontros presenciais do projeto para reuniões online.

Sendo assim, o projeto foi reestruturado em sua totalidade em um formato compreendendo atividades síncronas e assíncronas estruturadas envolvendo recursos digitais do Google Suite (UTFPR, 2020): o recurso de Google Meet para o desenvolvimento dos encontros síncronos do projeto, com interação oral ou escrita pelo chat; o Jamboard, também da mesma plataforma, para atividades de prévias ao filme (Apêndice B); o Google Forms, para a realização de quiz no formato de resposta dissertativa (Apêndice C); o Google Drive para as atividades de após a apresentação do curta, com compartilhamento de ideias levantadas nas discussões (Apêndice D). Além destes, utiliza-se também a plataforma 
de interação instantânea Mentimeter (2021), para discussão prévia ao filme (Apêndice B), os curta-metragens utilizados conforme o cronograma (Apêndice A), além de outros recursos para criação dos podcasts pelos participantes.

As atividades, materiais e recursos foram planejados a partir dos princípios de automaticidade, aprendizagem significativa, motivação intrínseca e investimento estratégico conforme proposto por Brown (2000) e explorados por diversos autores presentes neste artigo. A proposta será implementada nos meses de junho a julho de 2021 como projeto de extensão e terá continuidade como projeto de pesquisa a partir de sua implementação, gerando dados acerca da efetividade do projeto quanto ao desenvolvimento da oralidade, em particular da fluência em L2 a partir do uso de recursos digitais orientados por princípios cognitivos. Pretende-se, assim, contribuir para o desenvolvimento da língua inglesa como L2 em ensino remoto, porém engajado, intrinsecamente motivante e significativo.

\section{Nota}

1. No original: "the ability of the speaker to speak smoothly with minimal pauses or hesitations in the target language and accurately enough for the listener to understand" (RYCZEK, 2013, p. 32).

\section{Referências}

A THOUSAND Words. Direção: Ted Chung. S.l.: Ted Chung, 2008. 4 min, p\&b. Disponível em: https://film-english.com/product/a-thousand-words/. Acesso em: 15 mar. 2021.

AEBERSOLD, J. A.; FIELD, M. L. From Reader to Reading Teacher: issues and strategies for second language classrooms. New York: Cambridge University Press, 1997.

BROWN, H. D. Teaching by Principles: an interactive approach to Language Pedagogy. $2^{\text {a }}$ ed. New York: Pearson ESL, 2000.

CANVA. Editor de Flashcards. S.l.: Canva, 2021. Disponível em: https://www.canva. com/pt_br/criar/flashcards/. Acesso em: 27 mar. 2021.

CARNEGIE MELLON UNIVERSITY. Student Pandemic Short Films. Pittsburgh: CMU, 2020. Disponível em: https://www.cmu.edu/dietrich/english/news-andevents/2020/student- pandemic-short-films.html. Acesso em: 9 mar. 2021.

CHARTRAND, R. Social networking for language learners: Creating meaningful output with Web 2.0 tools. Knowledge Management \& E-Learning: An International Journal, v.4, no.1, p. 97-101, 2012. Disponível em: https://doi. org/10.34105/j.kmel.2012.04.009. Acesso em: 10 abr. 2021.

CREATIVE COMMONS. Mountain View, CA: Creative Commons, 2021. Disponível em: https://creativecommons.org/. Acesso em: 10 jun. 2021.

DE JONG, N.; PERFETTI, C. Fluency training in the ESL classroom: An experimental study of fluency development and proceduralization. Language Learning, v. 61, $\mathrm{n}^{\circ} 2$ 2, 533-568, 2011. Disponível em: http://www.pitt.edu/ perfetti/PDF/de\%20 Jong\%20Language\%20Learning. pdf. Acesso em: 18 jun. 2021.

DONAGHY, K. Film English. 2021. Website. Disponível em: https://film-english. com/. Acesso em: 10 abr. 2021.

DÕRNYEI, Z. Motivational strategies in the language classroom. Cambridge: Cambridge University Press, 2001. 
DÕRNYEI, Z; USHIODA, E. Teaching and researching motivation. $2^{a}$ Ed. Harlow: Longman, 2011.

EHRMAN, M.; DÕRNYEI, Z. Interpersonal dynamics in second language education: The visible and invisible classroom. Thousand Oaks, CA: Sage, 1998.

GAROFALO, D. Chegou a hora de inserir o podcast na sua aula. 24 set. 2019. Nova Escola, 2019. Disponível em: https://novaescola.org.br/conteudo/18378/chegoua-hora-de- inserir-o-podcast-na-sua-aula. Acesso em: 28 mar. 2021.

GIFT. Produção: Robin McKenna. S.1.: Gaudete Films, 2017. Trailer, 1a versão, Disponível em: https://creativecommons.org/2019/10/11/robin-mckennas-giftdocumentary-opens-today/. Acesso em: 03 abr. 2021.

GOOGLE. Sobre podcasts no Google. São Paulo: Google, 2021. Disponível em: https://support.google.com/podcast-publishers/answer/9476656?hl=pt-BR. Acesso em: 10 abr. 2021.

GUSSO, H. L. et al. Ensino superior em tempos de pandemia: Diretrizes à gestão universitária. Educ. Soc., Campinas, v. 41, e238957, 2020. Disponível em: $\quad$ http://www.scielo.br/scielo.php?script=sci_arttext\&pid=S010173302020000100802\&lng=en\&nrm=iso. Acesso em: 11 abr. 2021.

LEFFA, V. J. (Org.). Produção de materiais de ensino: teoria e prática. 2. ed. Pelotas: Educat, 2008.

LEFFA, V. J . Produção de Materiais para o Ensino de Línguas na Perspectiva do Design Crítico. In: TAKAKI, Nara Hiroko; MONTE MOR, Walkyria. (Orgs.). Construções de sentido e letramento digital crítico na área de línguas/ linguagens. Campinas: Pontes Editores, 2017, p. 243-265.

LONG, M. H.; DOUGHTY, C. J. (Ed.). The Handbook of Language Teaching. Hoboken: Blackwell Publishing Ltda, 2009.

LOSADA, C.; INSUASTY, E.A.; JAIME, M.F. The Impact of Authentic Materials and Tasks on Students' Communicative Competence at a Colombian Language School. PROFILE: Issues in Teachers' Professional Development, v. 19, nº 1, p. 89104 2017. Disponível em: http://dx.doi.org/10.15446/profile.v19n1.56763. Acesso em: 13 abr. 2021.

MEDEIROS, M. S. Podcasting: produção descentralizada de conteúdo sonoro. In: CONGRESSO BRASILEIRO DE CIÊNCIAS DA COMUNICAÇÃO, 28, 2005. Rio de Janeiro. Disponível em: http://bit.ly/OXKiUZ. Acesso em: 12 mar. 2021.

MENTIMETER. Estocolmo: Mentimeter,2021. Disponível em: https://www. mentimeter.com/. Acesso em: 13 mar. 2021.

QUARANTINE Film. Produção: Nina Edwards. In: CARNEGIE MELLON UNIVERSITY. Student Pandemic Short Films. Pittsburgh: CMU, 2020. 3 min, color. Disponível em: https://www.youtube.com/watch? $\mathrm{v}=\mathrm{icGhObCMGcg \& list=}$ PLopswAI4Jm- lcv4jK C38bsUqZk 4YVp74j\&t=6s. Acesso em: 10 mar. 2021.

ROHLING, N. Podcast e práticas de ensino-aprendizagem. In: CONEXÃO UTFPR. Potencialidades do Podcast como Ferramenta de Ensino (live). YouTube: Canal da UTFPR. 13 de abril de 2021. $61 \mathrm{~min}$, color. Disponível em: https://www. youtube.com/watch?v=SXZRpgGI3d8. Acesso em: 13 abr. 2021.

RYCZEK, M. Promoting Oral Fluency in the ESL classroom: An Introduction to the 4/3/2 Fluency Activity. Taichung: Asia University, 2013. Disponível em: https://core.ac.uk/reader/72791517. Acesso em: 10 abr. 2021.

SARAIVA, J. R. et al. LaSalle Cast: Produção do podcast como recurso pedagógico para educação a distância. ABED: Canoas, Jul. 2018. Disponível em: http://abed. org.br/hotsite/premio-abed-2018/2_colocado_EI_LASALLECAST.pdf. Acesso em: 05 abr. 2021. 
SEGALOWITZ, N. Second language fluency and its underlying cognitive and social determinants. International Review of Applied Linguistics in Language Teaching, v. 54, no. 2, p. 79-95, 2016. Disponível em: https://www.degruyter.com/ document/doi/10.1515/iral-2016- 9991/html. Acesso em 18 jun. 2021.

SEGALOWITZ, N.; FRENCH, L.; GUAY, J.D. What Features Best Characterize Adult Second Language Utterance Fluency and What Do They Reveal About Fluency Gains in Short-Term Immersion? Canadian Journal of Applied Linguistics. v. 20, p. 90-116, 2017. Disponível em: https://www.researchgate. net/publication/330528876_What_Features_Best_Characterize_Adult_Second_ Language_Utterance_Fluency_and_What_Do_They_Reveal_About_Fluency_ Gains_in_Short-Term_Immersion. Acesso em: 18 jun. 2021.

SINTEL. Short Film Creative Commons. Direção: Colin Levy. Produção: Ton Roosendaal. Escrito por Esther Wouda. Holanda: Blender Foundation, 2010. 14 min, color. Disponível em: https://www.youtube.com/watch?v=FUrrG_O5hLM. Acesso em: 07 abr. 2021.

SKEHAN, P. A cognitive approach to language learning. Oxford: Oxford University Press, 1998.

TOMITCH, L.M.B. Aquisição da leitura em língua inglesa. In: Diógenes Cândido de Lima. (Org.). Ensino e aprendizagem de língua inglesa. 1 ed. São Paulo: Parábola, 2009, v. 1, p. 191-201.

TOMLINSON, B. The importance of materials development for language learning. In: AZARNOOSH, M; ZERAATPISHE, M.; FARAVANI, A.; KARGOZARI, H.; Issues in Materials Development. Roterdam/Boston/Taipei: Sense publishers, 2016.

TUMOLO, C.H.S. 2014. Recursos digitais e aprendizagem de inglês como língua estrangeira. Ilha do Desterro, v. 1, nº. 66, p.203-238 jan/jun 2014. Disponível em: https://periodicos.ufsc.br/index.php/desterro/article/view/2175-8026.2014n66p203. Acesso em: 15 abr. 2021.

UMBRELLA. Direção, produção e roteiro: Helena Hilario e Mario Pece. YouTube. Rio de Janeiro: Stratostorm, 2020. 7 min, color. Disponível em: https://www. youtube.com/watch?v=Bl1FOKpFY2Q\&t=429s. Acesso em: 15 mar. 2021.

UMBRELLA MOVIE. Website. Design: Luis Mourão e Lídia Ganhito. 2021. Disponível em: http://www.umbrella.movie/. Acesso em: 10 abr. 2021.

UTFPR, Universidade Tecnológica Federal do Paraná. Google G Suite. 20 mar. 2020. Curitiba: UTFPR, 2020. Disponível em: http://www.utfpr.edu.br/noticias/patobranco/google-g-suite. Acesso em: 03 abr. 2021.

WINFIELD, Claudia Marchese (Coord.). Projeto de Extensão "Movie Talks". Departamento de Letras, Universidade Tecnológica Federal do Paraná. Pato Branco: UTFPR. 2018.

WINFIELD, Claudia Marchese (Coord.). Projeto de Extensão "Movie Talks Online". Departamento de Letras, Universidade Tecnológica Federal do Paraná. Pato Branco: UTFPR. 2021. (no prelo)

WOO, Y. et al. Implementing Authentic Tasks in Web-Based Learning Environments. EDUCAUSE Quarterly, v. 30, no 3, p.36-43, 2007. Disponível em: https://er.educause.edu/articles/2007/7/implementing-authentic-tasks-inwebbased-learning-environments. Acesso em: 10 abr. 2021.

Recebido em: 16/04/2021 Aceito em: 01/06/2021 


\section{APÊNDICE A}

\section{Cronograma e descrição das atividades do Projeto Movie Talks online (WINFIELD, 2021).}

\section{Atividades síncronas}

\begin{tabular}{|l|l|}
\hline 18/06/2021 & Sessão 1: Quarantine Film by Nina Edwards (QUARANTINE, 2020) \\
Acesso: https://www.youtube.com/watch?v=icGhObCMGcg\&list=PLopswAI4Jm- \\
lcv4jKC38bsUqZk4YVp74j\&t=6s \\
Mediação da atividade: coordenadora do projeto e acadêmico (a) do curso de Letras \\
participante do projeto.
\end{tabular}

\section{Atividades assíncronas}

\begin{tabular}{|l|l|}
\hline 21/06/2021 a & $\begin{array}{l}\text { Para as atividades assíncronas, propõe-se que os participantes escolham um dos curtas } \\
\text { selecionados para o projeto e preparem uma atividade de follow-up. Os participantes } \\
\text { poderão escolher a forma de produção e apresentação dessa atividade, algumas sugestões } \\
\text { sãoflashcards (CANVA, 2021), infográficos, posts e threads em redes sociais, histórias } \\
\text { em quadrinhos, vídeos curtos em aplicativos (Flipgrid ou TikTok, por exemplo), podcasts } \\
\text { ou blogs explorando os materiais de referência dos filmes ou as temáticas abordadas nas } \\
\text { obras. }\end{array}$ \\
\hline $\begin{array}{l}\text { 09/07/2021 a } \\
27 / 07 / 2021\end{array}$ & $\begin{array}{l}\text { Este período é reservado para o recebimento dos trabalhos para análise e devolutiva da } \\
\text { coordenadora e acadêmicos (as) participantes do projeto. }\end{array}$ \\
\hline $30 / 07 / 2021$ a & $\begin{array}{l}\text { Período reservado para os (as) participantes responderem o questionário de avaliação do } \\
\text { projeto. }\end{array}$ \\
\hline & \\
\hline
\end{tabular}




\section{APÊNDICE B}

\section{Atividades Propostas Prévias ao Filme}

As atividades prévias ao filme compreendem a ativação do vocabulário sobre infância e brinquedos, seguidas de uma pergunta de predição.

\section{Ativação de vocabulário}

Usando o recurso Jamboard do Google, a mediadora da sessão exibe a imagem abaixo para ativar o vocabulário relacionado ao tema "Toys".

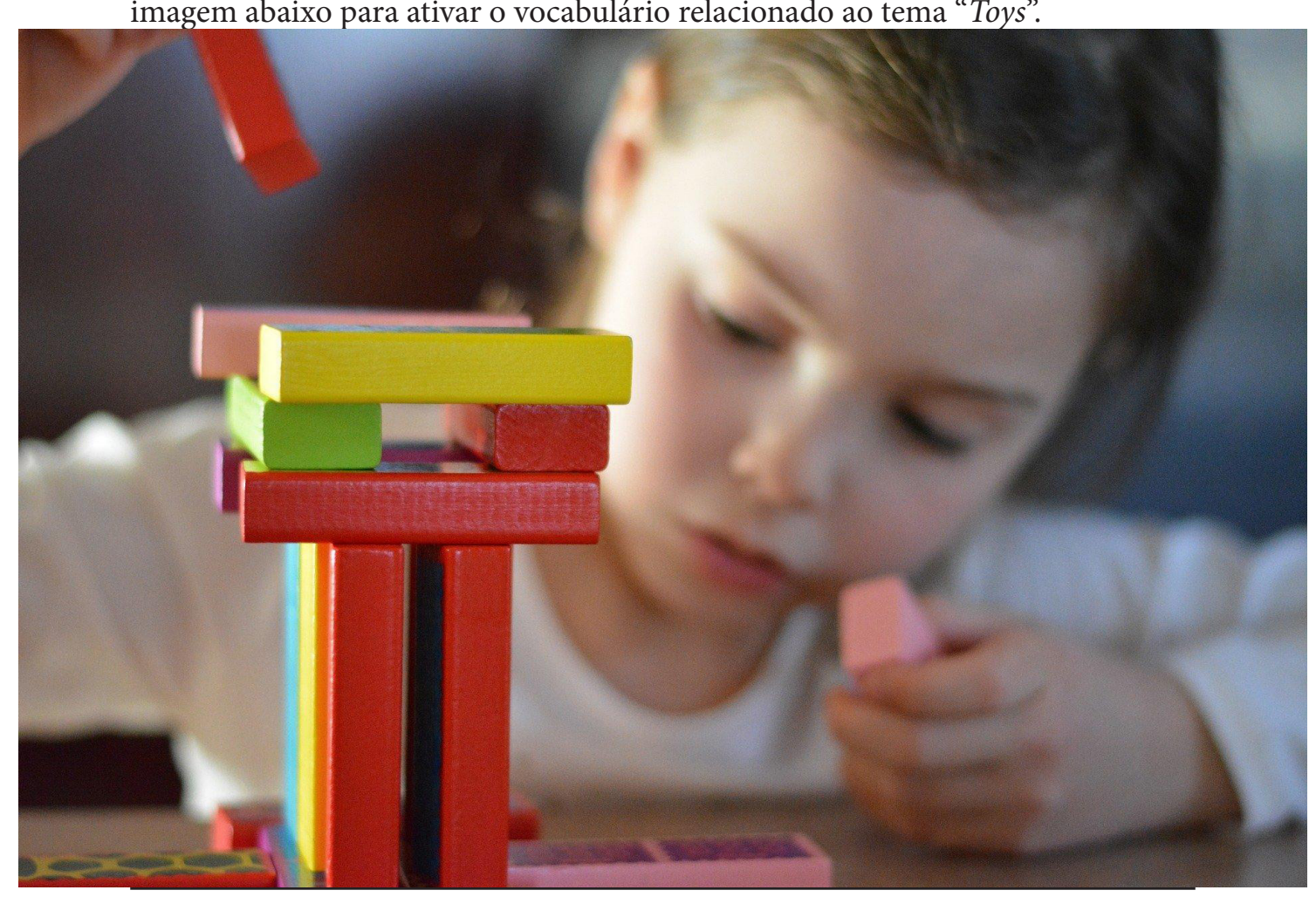

Figura 1. Fonte: https://pixabay.com/pt/photos/jogos-crian\%C3\%A7as-crian\%C3\%A7amenina-2801332/

Após exibir a imagem, a mediadora pede que os participantes acessem a plataforma de apresentação interativa Mentimeter (MENTIMETER, 2021) e respondam as perguntas a seguir:

1. What toys do you know in English?

As respostas à pergunta formarão uma nuvem de palavras.

2. What were your favorite toys when you were a child?

As respostas a esta pergunta serão na forma de resposta curta. 


\section{Mentimeter}

What were your favorite toys when you were a child?

Short answers are recommended. You have 250 characters left.

Submit

Fonte: autoral, utilizando o website Mentimeter (2021).

\section{Pergunta de Predição}

Converse com os participantes e comente sobre o curta-metragem exibido nesta sessão do projeto. Ele é uma criação brasileira e se trata da animação Umbrella, cuja narrativa é sobre um menino que prefere um guarda-chuva a qualquer outro brinquedo.

Assim, proponha a seguinte pergunta aos participantes: "Why might a young boy want an umbrella more than any toy?” (DONAGHY, 2020, p.3)

Nesta etapa, recomenda-se à mediadora que permita que os participantes expressem suas ideias, e oriente a discussão inicial com foco no sentido e na fluência, sem se ater a questões formais da língua inglesa. 


\section{APÊNDICE C}

\section{Atividades Propostas Durante o Filme}

\section{Predição dos eventos da narrativa}

Com o objetivo de trabalhar com o filme em etapas e gerar predições sobre o seu enredo, a mediadora deve exibir o filme em até 3 minutos e 40 segundos de duração. Após esse ponto, as perguntas abaixo, retiradas de (DONAGHY, 2020, p. 5) devem ser propostas:

1. What colour is the scarf the boy is wearing?

2. What colour are the boy's eyes?

3. What does the boy draw on the window?

4. How does the boy feel?

5. What colour are the girl's eyes?

6. How does the girl feel?

7. How does the boy react when he sees the yellow umbrella?

8. What do the mother and daughter bring to the home for children?

Os participantes serão convidados a responder às perguntas verbalmente ou pelo recurso chat do Google Meet. Assim como nas atividades prévias (Apêndice B), recomenda-se à mediadora que mantenha o foco da atividade na construção de sentido e na fluência, sem se ater a questões formais da língua inglesa. Ao responder às perguntas propostas, os participantes estarão construindo a narrativa gradualmente.

Subsequentemente, a mediadora exibe o curta até 5 minutos e 15 segundos e pede aos participantes que respondam ao quiz a seguir, apresentado por meio de Formulário Google:

9. Why did the boy(Joseph) take the yellow umbrella?

10. Where did he hide it?

\section{Recapitulação dos Eventos da Narrativa}

Após esta etapa, a mediadora exibe o filme até o seu final. Em seguida, pedese que os participantes enumerem os eventos do filme dispostos abaixo, conforme se lembrarem.

Number the statements below according to their order of occurrence:

( ) The little girl gave her yellow umbrella to Joseph

( ) Joseph and his father were homeless.

( ) Joseph was on a boat with his father.

( ) The little girl and Joseph grew up and got married.

( ) Joseph's father took him to an orphanage because he could not house or feed him. 


\section{APÊNDICE D}

\section{Atividades Propostas Após o Filme}

Discussão das temáticas envolvidas no curta-metragem e escrita colaborativa sobre as impressões geradas sobre o filme e a discussão.

Nesta etapa a mediadora deve abrir para impressões gerais sobre o filme, convidando os participantes a comentarem sobre o curta e expressarem suas impressões e ideias. Novamente, recomenda-se que o foco seja na expressão de ideias, mais do que em aspectos formais da língua. Temas como infância, questões sociais, abandono, recuperação, empatia podem ser evocados pela mediadora para incentivar a discussão.

Durante a discussão, a mediadora da atividade interage com os alunos, a professora orientadora do projeto irá compartilhar um documento com os participantes por meio do seu Google Drive. Nesse documento, a professora irá registrar as ideias e impressões conforme surgirem durante a discussão. Ao final de aproximadamente quinze minutos de discussão, a professora irá mostrar as anotações e convidar os participantes para fazerem ajustes no que foi anotado, de modo a criarem um texto de maneira colaborativa. Durante esse processo, serão trabalhados aspectos de escrita em língua inglesa como concordância verbal, estrutura de frases, uso de preposições, mecanismos coesivos como coesão referencial e conjunções. 